Article

\title{
Insight into One Health Approach: Endoparasite Infections in Captive Wildlife in Bangladesh
}

\author{
Tilak Chandra Nath ${ }^{1,2}{ }^{\oplus}$, Keeseon S. Eom ${ }^{1,3}$, Seongjun Choe ${ }^{1}\left(\mathbb{D}\right.$, Shahadat Hm ${ }^{4}$, Saiful Islam ${ }^{2}($, \\ Barakaeli Abdieli Ndosi ${ }^{1}$, Yeseul Kang ${ }^{5}$, Mohammed Mebarek Bia ${ }^{5}$, Sunmin Kim ${ }^{5}$, Chatanun Eamudomkarn ${ }^{5}$, \\ Hyeong-Kyu Jeon ${ }^{1}$, Hansol Park ${ }^{3,5, *}$ and Dongmin Lee ${ }^{3,5, *}$
}

1 Department of Parasitology, School of Medicine, Chungbuk National University, Cheongju 28644, Korea; tilak.parasitology@sau.ac.bd (T.C.N.); keeseon.eom@gmail.com (K.S.E.); vetazmo@gmail.com (S.C.); barakan@gmail.com (B.A.N.); jeonhk@cbnu.ac.kr (H.-K.J.)

2 Department of Parasitology, Sylhet Agricultural University, Sylhet 3100, Bangladesh; saiful1201082@gmail.com

3 International Parasite Resource Bank, Cheongju 28644, Korea

4 Rangpur Zoological and Recreational Garden, Rangpur 5404, Bangladesh; dr.hmshahadat@gmail.com

5 Parasite Research Center, Chungbuk National University, Cheongju 28644, Korea; paraseul47@gmail.com (Y.K.); bia_vet39@yahoo.fr (M.M.B.); claudine@chungbuk.ac.kr (S.K.); chatanune@yahoo.com (C.E.)

* Correspondence: hansol@chungbuk.ac.kr (H.P.); dongminlee@chungbuk.ac.kr (D.L.)

\section{check for} updates

Citation: Nath, T.C.; Eom, K.S.; Choe, S.; Hm, S.; Islam, S.; Ndosi, B.A.; Kang, Y.; Bia, M.M.; Kim, S.; Eamudomkarn, C.; et al. Insight into One Health Approach: Endoparasite Infections in Captive Wildlife in Bangladesh. Pathogens 2021, 10, 250. https://doi.org/10.3390/ pathogens 10020250

Academic Editors: Lawrence S. Young and Stefania Perrucci

Received: 12 January 2021

Accepted: 19 February 2021

Published: 23 February 2021

Publisher's Note: MDPI stays neutral with regard to jurisdictional claims in published maps and institutional affiliations.

Copyright: (c) 2021 by the authors. Licensee MDPI, Basel, Switzerland. This article is an open access article distributed under the terms and conditions of the Creative Commons Attribution (CC BY) license (https:/ / creativecommons.org/licenses/by/ $4.0 /)$.
Abstract: Introduction: Endoparasites in captive wildlife might pose a threat to public health; however, very few studies have been conducted on this issue, and much remains to be learned, especially in limited-resource settings. This study aimed to investigate endoparasites of captive wildlife in Bangladesh. Perception and understanding of veterinarians regarding one health and zoonoses were also assessed. Materials and Methods: A cross-sectional study was conducted from October 2019 to August 2020. A total of 45 fecal samples from 18 different species of wild animals (i.e., 11 species of mammals: herbivores, carnivores, and omnivores, six birds, and a single reptile species) were collected randomly. Parasitological assessments were done by modified formalin ether sedimentation technique and rechecked by Sheather's sugar floatation technique. Molecular identification of Spirometra spp. was conducted by amplifying the cytochrome $c$ oxidase 1 ( $\operatorname{cox} 1$ ) gene. Questionnaire surveys among 15 veterinarians and an in-depth interview (IDI) with a zoo officer were conducted. Results: Helminths (Spirometra sp., Capillaria sp., Ascaridia/Heterakis, opisthorchiid, strongyles, acuariid, hookworms, roundworms, and unidentified nematode larvae) and protozoa (coccidian oocyst) were identified, and the overall prevalence was $48.9 \%$ (22/45). The cox 1 sequences (341 bp) of the Bangladesh-origin Spirometra species from lion showed $99.3-99.7 \%$ similarity to the reference sequences of Spirometra decipiens (GenBank No: KJ599679.1; MT122766). The majority of study participants (86.6\%) agreed about the importance of endoparasite control in zoo animals, and 73.3\% expressed that the one health concept should be promoted in Bangladesh. Only $6.7 \%$ of veterinarians perceived confidence in diagnosing parasitic diseases and preventing antiparasiticidal resistance. Conclusions: In the present survey, we found a considerable prevalence of endoparasites in captive wildlife. For the first time, zoonotically important S. decipiens from lion was molecularly characterized in Bangladesh. Veterinarian training is required to improve parasite control knowledge and practice. This study highlights the need for routine parasitological assessment, promotion of one health, and improvement of the implementation of current parasite control strategies in zoo animals.

Keywords: endoparasites; captive wildlife; one health; Spirometra decipiens; Bangladesh

\section{Introduction}

One health is a collaborative, multisectoral, and transdisciplinary approach to promoting, improving, and protecting the health and wellbeing of all species by strengthening 
communication and collaboration between health professionals [1,2]. The World Organization for Animal Health (OIE) incorporates this concept as a collaborative global approach to understanding risks to humans, animals, and ecosystem health. Wildlife health, as defined by Stephen [3], is a dynamic social construct based on human expectations and knowledge. Health and sustainable maintenance of wildlife are mutually interdependent with the surrounding community and environment. The one health movement has heightened this focus by recognizing wildlife as a major source of zoonotic infections, thereby encouraging intensive research in the detection of wildlife pathogens [1,3]. As the natural habitats of many wild animals have been altered, degraded, or occupied by the growing human population, between 1970 and 2016, more than two-thirds of the global wildlife population has declined [4]. Zoological gardens or zoos exist to protect endangered animal species and to evaluate the need for biodiversity protection. Zoos also play a crucial role for aesthetic, recreational, and educational purposes $[5,6]$. However, wild animals maintained in captivity present challenges; controlling infectious diseases and maintaining good husbandry are essential [5]. Animals kept in crowded cages and in limited environments are stressed; the immune systems of animals become weak, making animals more susceptible to parasitic infections [6,7]. Animals with a regular deworming program usually do not show any major sign or symptoms of parasitic infection [6,7]; however, some endoparasites of wild animals may threaten the health of zoo workers, visitors, and surrounding city dwellers. Knowledge of the disease status of the zoo animals and appropriate screening are essential for public health safety and for the wellbeing of animals, as many pathogens can infect multiple host species $[5,8]$.

The successful implementation of any disease control program depends on adequate and sensitive methods for detecting and monitoring infections. Epidemiological data are also critical; however, application of such data is not easy and has to be done with care [9]. Understanding the relationships among biodiversity, health, and disease enhances policy development opportunities and ensures biodiversity conservation [10]. Veterinarians in zoos are leading to deal with health and management issues that threaten the long-term survival of wildlife species. Veterinarians come in direct contact with wild animals during clinical examination, specimen collection, biopsy procedure, surgery, hand-rearing of newborn animals, and postmortem examinations. A clear understanding of veterinarians about the interconnection between human, animal, and environmental health is needed to prevent and control zoonotic diseases [11]. To ensure public health safety and the protection of biodiversity, the combined efforts of human, animal, and ecosystem health is necessary. This combined effort is termed the "one health approach" and has become widely accepted within the health professions [12].

Almost all zoos in Bangladesh are located near city areas due to economic reasons, and close contact exists between human and captive animals. Animals are housed in close proximity to each other due to limited space and may serve as sentinels of disease for humans, wildlife, and domestic animals [13]. This could also be a threat to public health due to high household density around the areas where substantial barriers between zoo and locality are absent. So far, very few studies have been conducted on the parasites in captive wild animals in Bangladesh, and very little information is known about the occurrence of endoparasites. This cross-sectional pilot study was conducted as a part of the one health approach to assess endoparasites in captive animals in Bangladesh. The perception and understanding of veterinarians regarding one health were also assessed. Findings from this study may help zoo authorities to devise control strategies and raise awareness in related communities.

\section{Results}

Commonly given foods and antiparasitic medications to examined animals are shown in Table 1. A variety of foods are given to the animals according to their nutritional requirements depending upon the species, age, and physiology. In addition to grasses and plants, foodstuffs given to animals are pelleted formulated feeds, breads, fruits, vegetables, 
meat, and dairy products. A routine deworming program with several types of antiparasitic drugs is performed every 3-4 months to manage parasitic infections.

Table 1. Foods and antiparasitic medications given to examined animals.

\begin{tabular}{|c|c|c|c|c|}
\hline Animal & Scientific Name & Feed Given & Anthelmintic & Frequency \\
\hline Horse & Equus caballus & Grass, cereal grains & \multirow{5}{*}{$\begin{array}{c}\text { Albendazole } \\
\text { Or } \\
\text { Triclabendazole with } \\
\text { Levamisole }\end{array}$} & \multirow{5}{*}{ Every 3-4 months } \\
\hline Donkey & Equus asinus & Grass, cereal grains & & \\
\hline Black bear & Ursus americanus & $\begin{array}{l}\text { Bread, mixed boiled } \\
\text { feed (rice, milk, egg, } \\
\text { fruits, vegetables) }\end{array}$ & & \\
\hline Spotted deer & Axis axis & $\begin{array}{c}\text { Grass, cereal grains, } \\
\text { vegetables }\end{array}$ & & \\
\hline Porcupine & Hystrix indica & $\begin{array}{l}\text { Vegetables, grass, } \\
\text { cereal grains }\end{array}$ & & \\
\hline Lion & Panthera leo & Meat & \multirow{6}{*}{$\begin{array}{l}\text { Ivermectin } \\
\text { Or } \\
\text { Albendazole }\end{array}$} & \multirow{6}{*}{ Every 3-4 months } \\
\hline African civet & Civettictis civetta & Meat, fruits & & \\
\hline Wild cat (bon biral) & Felis silvestris & Meat & & \\
\hline Royal Bengal tiger & Panthera tigris & Meat & & \\
\hline Hanuman langur & Semnopithecus entellus & $\begin{array}{c}\text { Fruits, bread, } \\
\text { vegetables, cereal } \\
\text { grains, }\end{array}$ & & \\
\hline Monkey & Rhesus macaque & $\begin{array}{c}\text { Fruits, bread, cereal } \\
\text { grains, eggs }\end{array}$ & & \\
\hline Turkey & Meleagris gallopavo & $\begin{array}{l}\text { Nuts, commercial } \\
\text { poultry feed }\end{array}$ & \multirow{6}{*}{ Piperazine } & \multirow{6}{*}{ Every $3-4$ months } \\
\hline Peacock & Pavo cristatus & $\begin{array}{l}\text { Nuts, vegetables, } \\
\text { commercial poultry } \\
\text { feed }\end{array}$ & & \\
\hline Owl & Bubo bengalensis & Meat, nuts & & \\
\hline Vulture & Aegypius monachus & Meat, nuts & & \\
\hline Ostrich & Struthio camelus & $\begin{array}{c}\text { Fruits, bread, } \\
\text { commercial poultry } \\
\text { feed }\end{array}$ & & \\
\hline Emu & $\begin{array}{c}\text { Dromaius } \\
\text { novaehollandiae }\end{array}$ & $\begin{array}{c}\text { Fruits, bread, } \\
\text { commercial poultry } \\
\text { feed }\end{array}$ & & \\
\hline Python & Morelia spilota variegata & Meat & Albendazole & Every 3-4 months \\
\hline
\end{tabular}

Fecal examination results are shown in Table 2 and Figure 1 . We found a high infection rate; 22 out of 45 samples ( $48.9 \%$; $95 \%$ confidence interval $=36.1-59.0 \%$ ) were positive for parasitic infections. Out of 18 examined host species, 12 species were found positive for endoparasites. Among 45 examined animals, 12 animals showed mono-parasitic infection, while 10 animals were co-infected with different helminths and protozoa species. Concerning helminths, we identified gastrointestinal strongyles eggs in donkey, monkey, and hanuman (7/19,36.8\% of herbivores), Toxocara sp. in lion (2/10, 20.0\% of carnivores), Spirometra sp. in lion and African civet (3/10 30.0\% of carnivores), opisthorchiid eggs in tiger (1/10, 10.0\% of carnivores), Baylisascaris transfuga in black bear $(1 / 10,10.0 \%$ of carnivores), Capillaria sp. in turkey and peacock (4/15, 26.7\% of avian species), hookworm eggs in African civet and black bear (3/10,30.0\% of carnivores), roundworm eggs in vulture and peacock $(3 / 15,20.0 \%$ of avian species), and acuariid eggs in peacock $(1 / 15,6.67 \%$ of avian species). Furthermore, we found roundworm eggs in vulture and unidentified nematode larvae in emu. In case of protozoa, we found an oocyst of Eimeria spp. in spotted deer, turkey, and peacock $(4 / 15,26.7 \%$ of avian species; $1 / 29,3.5 \%$ of mammals) and an unidentified coccidian oocyst in emu (1/15, $6.7 \%$ of avian species). 
Table 2. Eggs and oocysts found during coprological examination according to taxonomic order of hosts.

\begin{tabular}{|c|c|c|c|c|c|c|c|}
\hline \multirow{2}{*}{ Type of Host } & \multirow{2}{*}{ Host } & \multirow{2}{*}{$\begin{array}{l}\text { Scientific } \\
\text { Name }\end{array}$} & \multirow{2}{*}{$\begin{array}{l}\text { No. of Examined } \\
\text { Samples }\end{array}$} & \multicolumn{2}{|c|}{ No. of Positives } & \multirow{2}{*}{$\begin{array}{l}\text { Egg or Oocyst } \\
\text { Observed }\end{array}$} & \multirow{2}{*}{ Size $(\mu \mathrm{m})(n=7)$} \\
\hline & & & & Helminths & Protozoa & & \\
\hline \multirow{7}{*}{$\begin{array}{l}\text { Mammals } \\
\text { (Carnivores/ } \\
\text { Omnivores) }\end{array}$} & Lion & Panthera leo & 2 & 2 & - & $\begin{array}{l}\text { Spirometra sp. } \\
\text { Toxocara sp. }\end{array}$ & $\begin{array}{l}61-65 \times 31-33 \\
65-68 \times 63-64\end{array}$ \\
\hline & Tiger & Panthera tigris & 2 & 1 & - & Opisthorchiid & $26-29 \times 13-14$ \\
\hline & African civet & Civettictis & 3 & 3 & - & Spirometra sp. & $60-63 \times 29-31$ \\
\hline & Bon biral & $\begin{array}{c}\text { civetta } \\
\text { Felis silvestris }\end{array}$ & 1 & - & - & $\begin{array}{c}\text { Hookworms } \\
-\end{array}$ & $\begin{array}{c}68-72 \times 39-41 \\
-\end{array}$ \\
\hline & & Ursus & & & & Hookworms & $72-77 \times 38-40$ \\
\hline & Black bear & americanus & 2 & 2 & - & $\begin{array}{l}\text { Baylisascaris } \\
\text { transfuga }\end{array}$ & $63-65 \times 58-60$ \\
\hline & 5 host species & & 10 & $8(80 \%)$ & - & \multicolumn{2}{|c|}{$\begin{array}{l}\text { Genera of helminth: } 5 \text {; Genera of } \\
\text { protozoa: } 0\end{array}$} \\
\hline \multirow{7}{*}{$\begin{array}{l}\text { Mammals } \\
\text { (Herbivores) }\end{array}$} & Donkey & Equus asinus & 5 & 2 & - & $\begin{array}{l}\text { Gastrointestinal } \\
\text { Strongyles }\end{array}$ & $67-69 \times 47-48$ \\
\hline & Horse & Equus caballus & 4 & - & - & - & - \\
\hline & Spotted deer & Axis axis & 2 & - & 1 & Eimeria spp. & $35-36 \times 19-24$ \\
\hline & Porcupine & Hystrix indica & 2 & - & - & -11 & - \\
\hline & Monkey & $\begin{array}{l}\text { Rhesus } \\
\text { macaque }\end{array}$ & 4 & 3 & - & $\begin{array}{l}\text { Gastrointestinal } \\
\text { Strongyles }\end{array}$ & $74-78 \times 43-46$ \\
\hline & Hanuman & $\begin{array}{l}\text { Semnopithecus } \\
\text { entellus }\end{array}$ & 2 & 2 & - & $\begin{array}{l}\text { Gastrointestinal } \\
\text { Strongyles }\end{array}$ & $68-71 \times 45-48$ \\
\hline & 6 host species & & 19 & $7(36.9 \%)$ & $1(5.3 \%)$ & \multicolumn{2}{|c|}{$\begin{array}{l}\text { Genera of helminth: } 1 \text {; Genera of } \\
\text { protozoa: } 1\end{array}$} \\
\hline \multirow{10}{*}{ Avian } & Turkey & $\begin{array}{l}\text { Meleagris } \\
\text { gallopavo }\end{array}$ & 2 & 1 & 1 & $\begin{array}{l}\text { Capillaria sp. } \\
\text { Eimeria spp. }\end{array}$ & $\begin{array}{l}48-51 \times 27-29 \\
31-35 \times 22-26\end{array}$ \\
\hline & Owl & $\begin{array}{c}\text { Bubo } \\
\text { bengalensis }\end{array}$ & 2 & - & - & - & - \\
\hline & Vulture & $\begin{array}{l}\text { Aegypius } \\
\text { monachus }\end{array}$ & 1 & 1 & - & Roundworms & $49-52 \times 28-29$ \\
\hline & Ostrich & $\begin{array}{l}\text { Struthio } \\
\text { camelus }\end{array}$ & 4 & - & - & - & - \\
\hline & & & & & & Capillaria sp. & $49-51 \times 28-29$ \\
\hline & Peacock & Pavo cristatus & 4 & 3 & 1 & Roundworms & $73-75 \times 49-51$ \\
\hline & & & & & & Eimeria spp. & $29-31 \times 18-21$ \\
\hline & Emu & Dromaius no- & 2 & 1 & 1 & $\begin{array}{l}\text { Unidentified } \\
\text { nematodes }\end{array}$ & $\begin{array}{l}\text { length.: } 2.1-2.4 \mathrm{~mm} \\
\text { width: } 0.79-0.84 \mu \mathrm{m}\end{array}$ \\
\hline & & & & & & $\begin{array}{l}\text { Coccidian } \\
\text { oocysts }\end{array}$ & $27-32 \times 21-24$ \\
\hline & 6 host species & & 15 & $6(40 \%)$ & $3(20 \%)$ & \multicolumn{2}{|c|}{$\begin{array}{c}\text { Genera of helminth: } 4 \text {; Genera of } \\
\text { protozoa: } 2\end{array}$} \\
\hline Reptile & Python & $\begin{array}{l}\text { Morelia spilota } \\
\text { variegata }\end{array}$ & 1 & - & - & - & - \\
\hline Total & 18 & & 45 & $21(46.5 \%)$ & $4(8.9 \%)$ & & \\
\hline
\end{tabular}

During laboratory examination, ovoid-shaped eggs sized about $61-65 \times 31-33 \mu \mathrm{m}$ with pointed ends were observed in the fecal samples of lion. According to these morphological characteristics, the parasite was assigned to Spirometra sp. We extracted DNA from Spirometra eggs, and sequence analysis based on the mitochondrial cox 1 gene $(341 \mathrm{bp})$ showed 99.3-99.7\% similarity to the reference sequences of S. decipiens (KJ599679.1; MT122766) and $90 \%$ similarity to S. erinaceieuropaei (KJ599680). A phylogenic tree constructed using maximum likelihood (ML) methods also showed the Spirometra sp. egg recovered in the present study clustered with S. decipiens (Figure 2). 


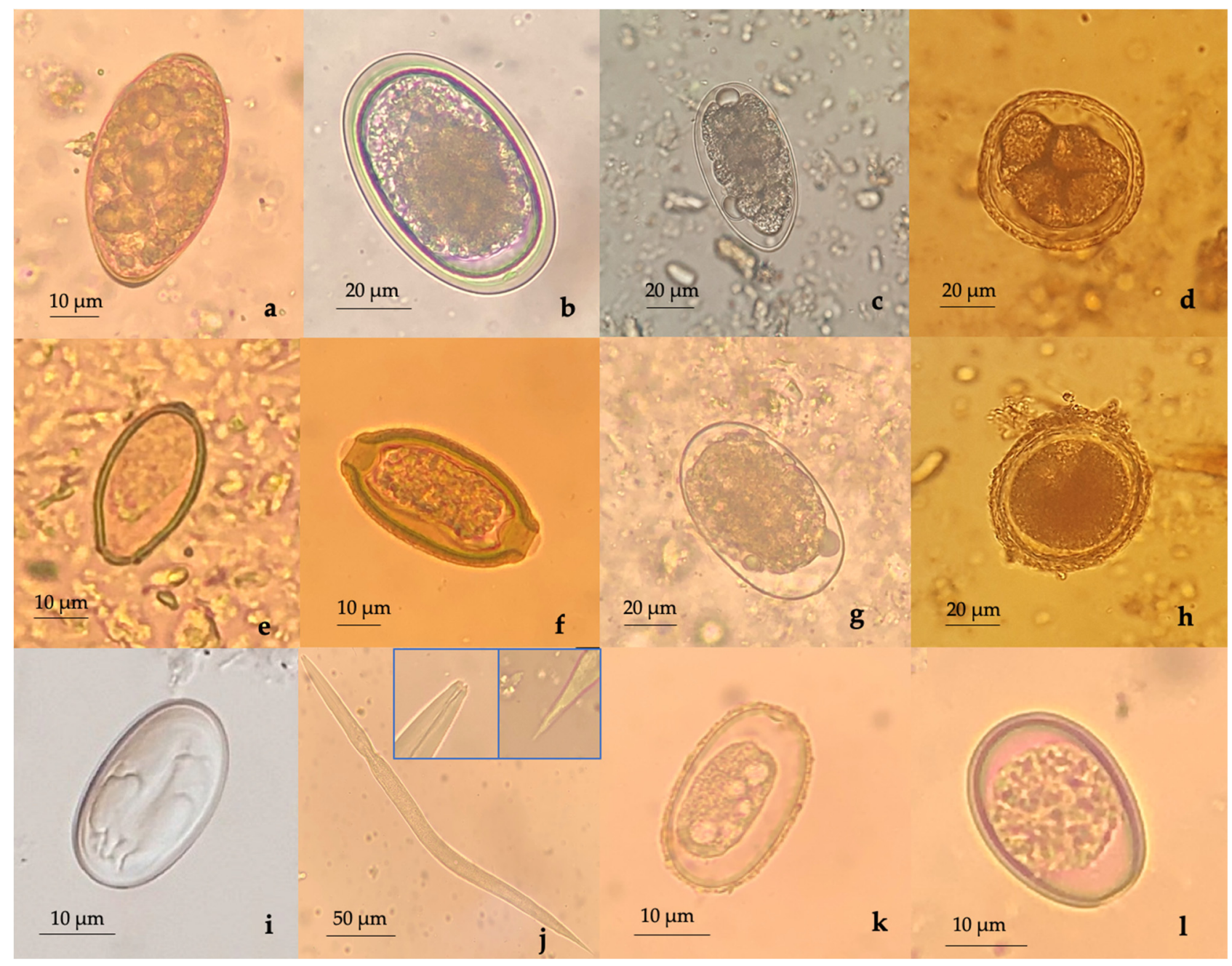

Figure 1. Identified endoparasites in captive wildlife: (a) Spirometra sp. egg (lion); (b) roundworm egg (peacock); (c) intestinal strongyle egg (monkey); (d) Baylisascaris transfuga egg (bear); (e) opisthorchiid egg (tiger); (f) Capillaria sp. egg (turkey); (g) hookworm egg (African civet); (h) Toxocara sp. egg (lion); (i) Acuaria sp. egg (peacock); (j) nematode larva (emu); (k) coccidian oocyst (emu); (1) Eimeria spp. oocyst (peacock).

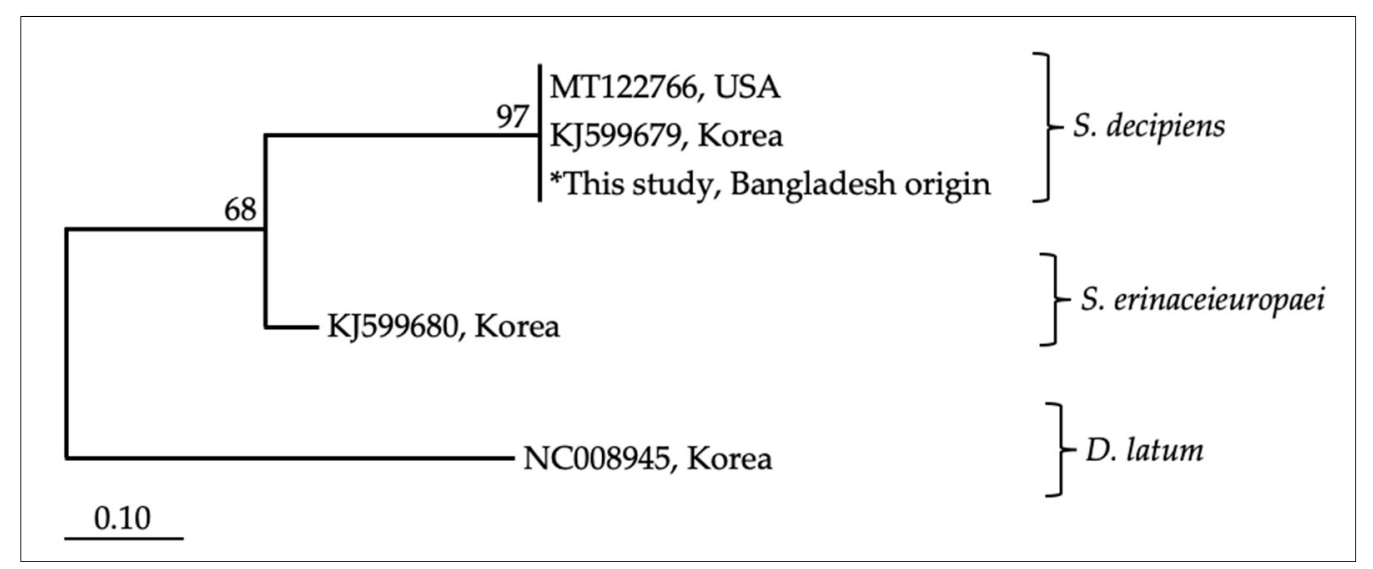

Figure 2. Phylogenetic relationships of Spirometra species based on cox 1 gene sequences reconstructed using maximum likelihood (ML) method. Bootstrap values are shown above branches. The scale bar represents $0.10 \%$ divergence. $\left({ }^{*}\right.$ indicates specimen used this study). 
An in-depth interview (IDI) with a zoo officer revealed that the leading barriers related to disease management were lack of training in zoonotic diseases and laboratory practices, lack of policy for workplace safety, absence of promotion activities on one health, and insufficient research on parasitic diseases. The following was mentioned:

"I am aware about my contributions to protect these valuable animals, as well as to ensure public health safety, but I did not get enough chance to attend training and information is also deficient ... We routinely administer anthelmintics to all animals, but laboratory facilities for fecal examination or efficacy monitoring are yet to be developed ... laboratory personnel are also lacking at this moment."

Of the veterinarians surveyed (Supplementary Table S1), the majority agreed/strongly agreed $(80.0 \%)$ parasites could be transmitted to humans/animals from the environment and vice versa; however, only $6.7 \%$ had enough confidence to diagnose, identify, and differentiate parasitic diseases. Regarding one health, the majority $(86.6 \%)$ agreed that one health could effectively control parasitic infections, and $73.3 \%$ expressed that the one health concept should be promoted by the national and local government in Bangladesh. Unfortunately, most of the respondents stated that resources to learn zoonoses and one health are lacking. Furthermore, most respondents perceived that they did not have had a sufficient understanding of antiparasiticidal resistance.

\section{Discussion}

The control of parasites is an essential feature of zoo management, as helminth infection can adversely impact the health of captive animals. Zoo animals are parasitized by many endoparasite species [7,14-16] and, in this study, several parasite species were identified in mammals and birds. Most endoparasites usually cause minimal discomfort to healthy animals; however, in conditions such as high population density, stress, and adaptation to new environments or extended periods in a confined space, these infections can cause disease [14]. Nearly half of the examined samples were positive for at least one parasitic species in this study. In zoos, control of these parasites should primarily focus on lessening infection pressures by administering anthelmintics. Although animals were treated with antiparasitic drugs periodically, the considerable infection rate observed in this study indicates that the current preventive measures applied are insufficient or that a high percentage of reinfections occur. Lack of quarantine, when new entered animals and existing animals are put together, and free-ranging stray animals could also be possible source for parasitic infection. Moreover, the frequent use of broad-spectrum anthelmintics combined with inappropriate dose and administration methods may lead to the development of resistance to anthelmintics [17]. In an experiment conducted by Young et al. [18], several gastrointestinal strongyles in captive wild ruminants showed a higher level of resistance to common anthelmintics such as levamisole and avermectin. To ensure anthelmintic efficacy, revision of parasite control strategies is required, including a greater emphasis on surveillance through periodic parasitological assessment.

The eggs/oocysts of 12 different types of parasites were observed in the study, and almost half of the examined animals were found infected with at least one parasite species, with some of them harboring potentially zoonotic parasites. Most of the parasites found in this study have fecal-oral routes of transmission that have commonly been reported in captive animals in various zoological gardens by several authors $[7,15,19]$. In most cases, animals may acquire the infections through contaminated foods, water, and even staff and visitors of the zoo. Humans have been reported to play a role in transmitting parasites through their shoes, clothes, hands, food, or working tools and act as vectors [20]. The environment can also play an important role in the transmission of parasites and can be contaminated with parasitic eggs or larvae through improperly disposed fecal materials [20]. Feeding raw or undercooked fish and meat might be a potential source for trematode and cestode infection [21] as tissues of intermediate or paratenic hosts contain larval forms of parasites. In this study, interviews with a zoo officer revealed that animal cages and facilities were cleaned and fecal materials were removed from animal 
cases regularly. However, during observation, indoor and outdoor facilities were not found to be cleaned adequately. Preventing environmental contamination by eggs and larvae of parasites could be one of the key steps to stopping the transmission of parasites to the wildlife. Regular monitoring for sanitation and cleaning is necessary to minimize the risk. Zoos also need to take measures to exclude rodents such as rats and mice from food storage and preparation areas, as those rodents can serve as a reservoir host of many zoonotic helminths such as Baylisascaris spp., Toxocara sp., hookworms, and Capillaria hepatica [22,23].

The present findings show that parasites can be common in zoo birds since four out of six examined avian species were coprologically positive and most of the infected birds had mixed infections. Papini et al. [20] mentioned that zoo birds were about 15 times more likely to develop mixed infections than their pet counterparts. In zoos, closely related species were all housed together, and many bird nematodes can have a wide host range. We observed Ascaridia spp./Heterakis spp. eggs in the fecal samples of avian species. However, these two genera of nematodes cannot be differentiated on the basis of egg morphology and size [24]. Ascarids are included in the most important intestinal nematodes infecting birds, since they are often the cause of intestinal obstruction, intestinal perforation, and death of infected birds [25]. In most birds, coccidiosis may be caused by species of the genera Eimeria or Isospora, and species of both genera have been reported in emu [26-28]. The differentiation of these two genera is based on the morphology of mature (sporulated) oocysts, since mature Eimeria oocysts show four sporocysts each containing two sporozoites, while mature Isospora oocysts show two sporocysts each containing four sporozoites [29]. Therefore, further research is required to identify the species infecting the emu in this study. We were not able to identify the nematode species found in emu feces which measured 2.1-2.4 $\mathrm{mm}$ in length by $0.79-0.84 \mathrm{~mm}$ in width. However, according to its morphology, this nematode could be either a free-living stage of Dromaestrogylus sp. or a free-living nematode species.

Helminth infection was more common than protozoal infection, with helminth eggs observed in $21(46.7 \%)$ animals, while protozoans were observed in four $(8.9 \%)$ of the total positive animals. Interestingly, only one cestode and one trematode were detected in this study. The probability of trematode and cestode infections in captive animals is lower, as the life cycle of these helminths is indirect; they require one or more intermediate hosts for their development and transmission [30,31]. Since animals in zoos are kept in closed enclosures, giving very limited access to the intermediate hosts, their intermediate hosts are less likely accumulated in the enclosure [32]. However, in our study area, strong barriers between the outer and inner environment of the zoo were absent, and this could be the reason for the transmission these parasites. Feeding tissues of larva-infested intermediate or paratenic hosts could be the source of infection in these cases; animals could have been infected with cestode or trematode larvae through the consumption of raw or undercooked fish or meat, or they could have become intermediate hosts when accidentally ingesting worm eggs [21,33]. Most of the parasites of wild animals, especially from carnivores, can also infect other animals and humans; therefore, they have public health importance [9]. Helminths found in this study, such as Baylisascaris sp., Spirometra sp., Toxocara sp., hookworms, and opisthorchiid, are well-recognized zoonotic agents $[6,15,21,34]$. Although not zoonotic, other helminth species identified in this study, especially from wild herbivores, may also infect other mammal hosts [18]. Therefore, it is emphasized that visitors, veterinarians, and zoo staff who have contact with these animals must take precautions to avoid infection and possible zoonotic transmission.

Wild animals play a critical role in the epidemiology of helminths, as they may be considered as a potent reservoir for many roundworms with implications in constant transmission to human populations and pet animals [34]. One of the most important zoonotic helminths observed in bears is Baylisascaris sp. Baylisascaris species infects more than 50 different animal species, including humans and wild mammals. Although egg morphology alone is not sufficient to specify B. transfuga, other ascarid nematodes can be excluded from the differential diagnosis on the basis of epidemiology and available 
studies. B. transfuga is a ubiquitous roundworm, reported worldwide, which exclusively infects bears both free ranging and in captivity [35,36]. Eggs of this parasite have a thick, impermeable, desiccation-resistant lipid layer [37] and can remain infective for at least 15 months under artificial conditions [38]. Humans, especially zoo staff and trappers, can be infected from a contaminated environment. In humans, Baylisascaris larvae may cause ocular and visceral larva migrans, which may become fatal when larvae invade the central nervous system [22]. Other important potentially zoonotic parasites identified in this study were Toxocara spp. infecting the lion, i.e., T. cati which is transmitted when infective larva-infested eggs are ingested by human hosts [39]. The disease is distributed worldwide, but particularly highly in tropical lower-resource countries. It causes significant morbidity and poses an important, yet largely unaddressed public health problem in areas of high prevalence [40]. The majority of Toxocara infections remain asymptomatic, whilst a minority develop fatal diseases of visceral larva migrans, ocular larva migrans, and covert toxocariasis. The eggs hatch in the small intestine, and the larvae migrate to the liver, lungs, eyes, and other body organs, where they cause tissue necrosis, chronic liver disease, edema, hemorrhage, and eosinophilia $[9,39]$. Hookworms can pose serious public health hazards and display a high pathogenic potential due to their blood-feeding behavior [34]. Human infection with hookworm species commonly causes cutaneous larval migrans, with painful, itchy eruptions along the path of migrating larvae $[9,16]$. In the lungs, these larvae infiltrate the alveoli and migrate up to trachea, from where they reach the intestine. People involved in direct contact with soil and animals are at risk of acquiring hookworm infection [34,41]. Therefore, it is important that zoo staff adopt proper hygiene, including hand washing and wearing personal protective equipment, to avoid contact with hookworm larvae. In this study, zoonotically significant opisthorchiid eggs were also identified from tiger. Opisthorchiid flukes, especially Clonorchis sp. and Opisthorchis sp., infect millions of people, particularly in Southeast Asia, Eurasia, and North America [42]. We did not distinguish the genera of opisthorchiid flukes as egg morphometry alone fails to accurately distinguish the species [42]. Both genera were reported from Panthera spp. Seryodkin et al. [43] reported C. sinensis from Siberian tigers (Panthera tigris altaica) and Stuti et al. (2012) [44] reported Opisthorchis sp. from leopard (Panthera pardus). However, no study was found regarding opisthorchiid infection in Royal Bengal tiger (Panthera tigris). Eating raw or undercooked fish, coupled with the inadequate sanitation facilities, provides a perfect environment for the spread of opisthorchiid infections. Improper disposal of faces leads to the continuation of the life cycle by contamination of the environment and infection of intermediate hosts $[9,43]$. Spirometra spp. represent another neglected parasitic agent with zoonotic potential, since they are the cause of sparganosis in humans and animals. Sparganosis has been reported worldwide, but most cases occur in Asia and Americas [33,45-47]. Human infection may occur in various ways, including drinking contaminated water containing larvae or first intermediate hosts and ingesting raw or undercooked meat from infected intermediate secondary hosts or paratenic hosts (frogs, snakes, and game such as feral swine) [45]. Almost all zoos in Bangladesh are located in urban and crowded areas with inadequate sanitation facilities that favor the transmission of zoonotic parasites. Moreover, loose animals such as rodents, birds, and even stray dogs and cats may also contribute to the transmission of parasites to animals kept in the zoo.

Although human sparganosis has been reported in neighboring countries such as Myanmar [48] and India [49], Spirometra information in Bangladesh is limited, and genetic analysis has not been done on the species. From a heavily infected lion, we successfully extracted the DNA of the spirometriid eggs isolated from fecal samples. According to the mitochondrial cox 1 sequences available in the NCBI (National Center for Biotechnology Information) database, this study has shown that the Bangladesh-originated Spirometra species can be identified as $S$. decipiens. However, the taxonomy of the genus Spirometra is still unclear, and there is considerable controversy in the literature [47]. Although S. decipiens from Korea [50], S. ranarum from Myanmar [48], and S. erinaceieuropaei from China [45] were reported and claimed as individual species, some researchers reported $S$. decipiens 
and $S$. ranarum as synonyms of $S$. erinaceieuropaei [51,52]. In addition to morphological differences, Jeon et al. [48] analyzed the mitochondrial genomes of three Spirometra spp. and showed nucleotide divergence among S. decipiens, S. erinaceieuropaei, and S. ranarum. Recently, Yamasaki et al. [47] re-examined all three Spirometra species on the basis of the mitochondrial cox 1 gene and stated that S. decipiens and S. ranarum from Asia are probably conspecific with $S$. mansoni. In this regard, further studies are needed to clarify the taxonomic status of Spirometra.

One health offers a valuable platform for implementing policies and strategies in the health biodiversity context to address the public health challenges of the 21st century [2,12]. Zoonotic diseases are increasingly recognized as a serious threat to public health, and it is estimated that $70 \%$ of zoonotic diseases originate from wildlife. An estimated 700 million people worldwide visit zoos each year [53], and interaction between humans and captive animals is increasing gradually with the potential of zoonotic disease transmission. Understanding disease transmission as a whole and understanding the role of the captive animals in human, animal, and environmental health is considered a vital requirement for the one health approach. However, to design and implement control measures, it is necessary to identify and understand the opportunities and challenges that exist in the contextual settings in Bangladesh. Veterinarians are often placed in a fundamental position to maintain relationships of captive animals with humans and other animals, as well as their effect on the surrounding environment, disease spread, natural resource availability, culture, and society. Appropriate knowledge of veterinarians regarding zoonosis and one health will ensure animal welfare and broaden the perspective to maintain all activities in a healthy manner [54]. In this study, we sought to determine the attitude, perception, and understanding of veterinarians concerning parasitic zoonoses and one health. Respondents showed a good perception of parasitic zoonoses and a positive attitude that one health approach can effectively ensure animal and human health. However, practical frameworks for professionals to prevent parasitic zoonosis and promote the one health approach are lacking in Bangladesh. Zoo workers do not have sufficient understanding and equipment to protect themselves from zoonoses at the workplace. Despite a good attitude, there is a need to improve their knowledge to enhance public health security. For effective prevention and control of zoonotic diseases, veterinarians need to understand the interactions among humans, animals, and the environment [11].

There are several limitations as our study aimed to create a baseline inventory of key endoparasites species infecting captive animals in Bangladesh. It was not our intention to provide a comprehensive overview of all species or to provide species-level identification. Due to a deficiency of samples, we were unable to extract DNA from all fecal samples. Furthermore, we were unable to pinpoint the source of infection in most animals; in most cases, zoo authorities had no data regarding the origin of the animals. Despite several limitations, we identified several parasite species that will increase attention in future research.

\section{Materials and Methods}

\subsection{Study Area, Study Population, and Sample Collection}

The study was conducted from October 2019 to August 2020. Forty-five fresh fecal samples were collected from 18 different species of mammals, birds, and reptiles captured at a public zoo in Bangladesh. Samples were collected from clinically healthy animals only (Table 1). Symptomatic and isolated animals were excluded as per regulation of the zoo administration. All samples were fixed with $10 \%$ formalin and $70 \%$ ethanol. Fixed samples were transported to the Department of Parasitology, School of Medicine, Chungbuk National University, South Korea. The questionnaire survey was conducted among 15 veterinarians, and an in-depth interview was conducted with a zoo officer.

\subsection{Coprological Examination}

Formalin-fixed fecal samples were processed for examination. For the modified formalin ether sedimentation technique, the procedure began with thorough mixing of 
the fecal suspension and sieving through gauze into a test tube. The test tube was then vigorously shaken, followed by the addition of $3 \mathrm{~mL}$ of ether as an extractor of fat and fecal debris. After centrifugation for $5 \mathrm{~min}$ at $1500 \mathrm{rpm}$, the supernatant was discarded, and the sediment was examined using a light microscope. For Sheather's sugar floatation technique, the fecal sample was suspended in distilled water and sieved with a double layer of gauzes, transferred to a test tube, and centrifuged at $1500 \mathrm{rpm}$ for $5 \mathrm{~min}$. The supernatant was then poured off, and Sheather's sugar solution (approximately 1.27 specific gravity) was added as a flotation solution. The mixture was then vigorously shaken and centrifuged at $1000 \mathrm{rpm}$ for another $10 \mathrm{~min}$. The tube was filled with Sheather's sugar solution up to the upper meniscus and covered with a coverslip. About 15 min later, the coverslip was removed, and the sample was placed onto a glass slide and examined under the microscope. The identification of eggs, ova, and larva was made on the basis of standard keys such as size, shape, nature of the shell, and nature of germinal cells $[24,55]$.

\subsection{PCR Amplification and Sequencing for Zoonotically Significance Eggs}

DNA extraction was done from the lion's fecal sample (fixed with $70 \%$ ethanol) that was microscopically positive for Spirometra sp. eggs, using the QIAamp DNA Stool Kit (Qiagen, Hilden, Germany), according to the manufacturer's instructions. However, elution was repeated twice using distilled water instead of elution buffer. The concentration and purity of DNA were measured (NanoDrop Spectrophotometer, Thermo Fisher Scientific Solutions Co. Ltd., Seoul, Korea), and it was stored at $-20{ }^{\circ} \mathrm{C}$ before use. A region within mitochondrial cytochrome $c$ oxidase subunit I (cox1) was amplified and sequenced. PCR and DNA sequencing were performed according to established pro-

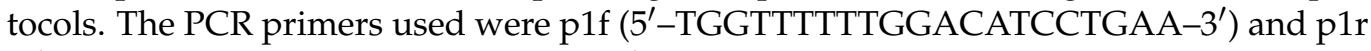
$\left(5^{\prime}\right.$-ATCACATAATGAAAGTGAGCC- $\left.3^{\prime}\right)$ [56]. The PCR reactions were performed in a Kyratec PCR Thermal Cycler (Queensland, Australia). The PCR was carried out in a final reaction mixture containing $30 \mu \mathrm{L}$, including $1 \mu \mathrm{L}$ of each primer $(10 \mathrm{pmol}), 1 \mu \mathrm{L}$ of generic DNA, $8 \mu \mathrm{L}$ of $5 \times$ PCR Master Mix (ELPIS biotech, South Korea), and $19 \mu \mathrm{L}$ of distilled water. A negative control was applied in each run. PCR conditions were as follows: $94{ }^{\circ} \mathrm{C}$ for $3 \mathrm{~min} ; 94{ }^{\circ} \mathrm{C}$ for $1 \mathrm{~min}, 48^{\circ} \mathrm{C}$ for $1 \mathrm{~min}$, and $72{ }^{\circ} \mathrm{C}$ for $1 \mathrm{~min}$ for 35 cycles; $72{ }^{\circ} \mathrm{C}$ for $10 \mathrm{~min}$. When amplifications did not work adequately, the annealing temperature was changed and adjusted. The PCR products were run on a 1\% agarose gel and visualized using an ultraviolet (UV) transilluminator. DNA sequencing was performed by a company (Cosmogenetech, Seoul, Korea). The obtained sequences were assembled with Geneious program 9.0 (Biometer, Auckland, New Zealand). Sequences were aligned using ClustalW multiple alignments implanted in MEGA7 [57,58]. Alignments were trimmed to the length of the shortest sequence. Sequencing analysis was carried out by BLAST (Basic Local Alignment Search Tool) algorithms and databases from the National Center for Biotechnology Information. Phylogenetic trees were constructed with four taxa of Diphyllobothriidae comprising S. decipiens (GenBank no. KJ599679; MT122766; LC328899), S. erinaceieuropaei (GenBank no. KJ599680), and Dibothricephalus latus (=Diphyllobothrium latum, GenBank no. NC008945; as outgroup), using maximum likelihood (ML) algorithms. Bootstrap values were calculated using 1000 replicates. The multiple alignments were performed with the program Muscle [59] and Hasegawa-Kishino-Yano (HKY + G) was chosen according to the Modeltest using MEGA7 [57]. To describe the best substitution patterns, the lowest BIC scores (Bayesian information criterion) were considered. The generic DNA used in the present study was stored in the International Parasite Resource Bank, Korea (PRB001200).

\subsection{Data Collection and Analysis}

A semi-structured questionnaire survey among 15 veterinarians was conducted to access knowledge and perception of zoonoses and one health. One in-depth interview with a zoo officer was also conducted to understand the current management and practices required to facilitate sustainable parasite control regimens. Interviews were conducted through an online platform due to government regulations of social distancing to prevent 
COVID-19. The semi-structured questionnaire consisted of 15 questions (four open-ended; 11 close-ended), and it was designed to obtain information related to study objectives. Respondents were given the opportunity to include additional information for some openended questions. An online questionnaire was created using web-based software, Survey Monkey, and the link was distributed via email to respondents. The IDI was conducted using an interview guide designed to assess the level of knowledge, attitude, practices, awareness, current strategies, existing barriers, opportunities, challenges, and future suggestions associated with parasite control and implementing the one health approach. The IDI was conducted through an online platform (zoom.us) and lasted about $40 \mathrm{~min}$. All collected data (both questionnaire and transcribed text) were double-checked by research assistants and rechecked by the principal researcher for missing data or incorrect entries. Frequency tables and cross-tabulations were produced for each study variable. Data were analyzed using STATA 13.1 data analysis software [60]. Descriptive statistics were used to tabulate and describe the data.

\subsection{Ethics Permission}

The study protocol was reviewed and approved (Approval No. EC/2020/59) by the Department of Parasitology, Chungbuk National University, Korea, and the Department of Parasitology, Sylhet Agricultural University, Bangladesh. Registered veterinarians collected the study materials.

\section{Conclusions}

In this study, a considerable prevalence of endoparasites was observed in captive wildlife in Bangladesh. Some parasites found in this study are well known as human pathogens and might be a potential source of zoonotic transmission. Participants showed a good perception of zoonoses and one health; yet, relative education and capacity building training are required to translate this perception into practice. To our knowledge, this is the first molecular identification of S. decipiens in Bangladesh, and further study to determine the exact taxonomic status of Spirometra species in this area is required. Results from this study emphasize the need for integrated approaches with greater emphasis on regular parasite surveillance and monitoring to ensure sustainable parasite control.

Supplementary Materials: The following are available online at www.mdpi.com/xxx/s1, Table S1: Perception and understanding of veterinarians $(N=15)$.

Author Contributions: Conceptualization, K.S.E., D.L., H.P., and T.C.N.; questionnaire development, T.C.N.; formal analysis, H.-K.J., D.L., H.P., and T.C.N.; methodology, H.-K.J., S.C., T.C.N., D.L., H.P., and C.E.; resources, S.H., S.I., and T.C.N.; validation, K.S.E., S.C., D.L., and H.P.; writing-original draft, T.C.N.; review and editing, D.L., H.P., S.C., K.S.E., M.M.B., Y.K., and B.A.N. All authors have read and agreed to the published version of the manuscript.

Funding: This work was supported by the Basic Science Research Program through the Chungbuk techno-park funded by Chungcheongbuk-do, Korea and the Post-Doctoral Fellowship Program funded by the Ministry of Education of the Republic of Korea through the Chungbuk National University in 2019. The funders had no role in study design, data collection and analysis, decision to publish, or preparation of the manuscript.

Institutional Review Board Statement: Not applicable.

Informed Consent Statement: Informed consent was obtained from all participants involved in the study.

Data Availability Statement: All samples and genomic DNA were stored in the International Parasite Resource Bank (iPRB), Korea, and are available from the corresponding authors or first author (tilak.parasitology@sau.ac.bd) on reasonable request. The data are not publicly available due to privacy or ethical reasons.

Acknowledgments: The authors thank Rangpur Zoological and Recreational Garden, Bangladesh, and Shiblee Sadik Sabuj for supporting field activities and collection of samples. 
Conflicts of Interest: No potential conflicts of interest are declared by the authors.

\section{References}

1. One Health. One Health Commission. 2010. Available online: www.onehealthcommission.org/ (accessed on 19 September 2020).

2. Atlas, R.M. One Health: Its Origins and Future. Current Topics in Microbiology and Immunology; Springer: Berlin, Germany, 2012.

3. Stephen, C. Toward a modernized definition of wildlife health. J. Wildl. Dis. 2014, 50, 427-430. [CrossRef]

4. Almond, R.E.A.; Grooten, M.; Petersen, T. (Eds.) Living Planet Report 2020-Bending the Curve of Biodiversity Loss; WWF: Gland, Switzerland, 2020.

5. Kirkwood, J.K. Special challenges of maintaining wildlife in captivity in Europe and Asia. Rev. Sci. Tech. Off. Int. Epiz. 1996, 15, 309-321. [CrossRef]

6. Schieber, M.C.; Strkolcova, G. Prevalence of Endoparasites in Carnivores in a Zoo and a Wolves park in Germany. Folia Vet. 2019, 63, 54-59. [CrossRef]

7. Parsani, H.R.; Momin, R.R.; Maradin, M.G.; Veer, S. A survey of gastrointestinal parasites of captive animals at Rajkot munipical corporation zoo, Rajkot, Gujarat. Zoos' Print J. 2001, 16, 604-606. [CrossRef]

8. Cleaveland, S.; Larurenson, K.; Milengeya, T. Impacts of Wildlife Infections on Human and Livestock Health with Special Reference to Tanzania: Implications for Protected Area Management; Osofsky, S.A., Cleaveland, S., Karesh, W.B., Kock, M.D., Nyhus, P.J., Starr, L., Yang, A., Eds.; Conservation and Development Interventions at the Wildlife/Livestock Interface: Implications for Wildlife, Livestock and Human Health; IUCN: Gland, Switzerland; Cambridge, UK, 2005.

9. Mackenstedt, U.; Jenkins, D.; Romig, T. The role of wildlife in the transmission of parasitic zoonoses in peri-urban and urban areas. Int. J. Parasitol. Parasites Wildl. 2015, 4, 71-79. [CrossRef]

10. Romanelli, C.; Cooper, H.D.; de Souza, D.B.F. The integration of biodiversity into One health. Rev. Sci. Tech. Off. Int. Epiz. 2014, 33, 487-496. [CrossRef] [PubMed]

11. Omemo, P.; Ogola, E.; Omondi, G.; Wasonga, J.; Knobel, D. Knowledge, attitude and practice towards zoonoses among public health workers in Nyanza province, Kenya. J. Public Health Afr. 2012, 3, e22. [CrossRef]

12. Deem, S.; Dennis, P. Role of zoos in one health. One Health Newsl. 2012, 5, 4-7.

13. Deem, S.L. Conservation Medicine to One Health: The Role of Zoologic Veterinarians; Miller, R.E., Fowler, M.E., Eds.; Fowler's Zoo and Wild Animal Medicine; Saunders Elsevier: St. Louis, MO, USA, 2015; pp. 698-703.

14. Sprenger, L.K.; Yoshitani, U.Y.; Buzatti, A.; Molento, M.B. Occurrence of gastrointestinal parasites in wild animals in State of Paraná, Brazil. An. Acad. Bras. Ciênc. 2018, 90, 231-238. [CrossRef] [PubMed]

15. Adetunji, V.E. Prevalence of gastro-intestinal parasites in primates and their keepers from two zoological gardens in Ibadan, Nigeria. Sokoto J. Vet. Sci. 2014, 12, 25-30.

16. Fagiolini, M.; Riccardo, P.L.; Piero, L.; Paolo, C.; Riccardo, M.; Stefania, P. Gastrointestinal parasites in mammals of two Italian zoological gardens. J. Zoo Wild. Med. 2010, 41, 662-670. [CrossRef] [PubMed]

17. Shalaby, H.A. Anthelmintic Resistance; How to Overcome it? Iran. J. Parasitol. 2013, 8, 18-32. [PubMed]

18. Young, K.; Jensen, J.; Craig, T. Evaluation of Anthelmintic Activity in Captive Wild Ruminants by Fecal Egg Reduction Tests and a Larval Development Assay. J. Zoo Wildl. Med. 2000, 31, 348-352. [PubMed]

19. Lim, Y.A.L.; Ngui, R.; Shukri, J.; Rohela, M.; Mat Naim, H.R. Intestinal parasites in various animals at a zoo in Malaysia. Vet. Parasitol. 2008, 157, 154-159. [CrossRef]

20. Papini, R.; Girivetto, M.; Marangi, M.; Mancianti, F.; Annunziata, G.A. Endoparasite Infections in Pet and Zoo Birds in Italy. Sci. World J. 2012, 2012, 253127. [CrossRef]

21. Utzinger, J.; Bergquist, R.; Olveda, R.; Zhou, X.N. Important helminth infections in Southeast Asia; Diversity and Potential for Control and Prospects for Elimination. Adv. Parasitol. 2010, 72, 1-30. [PubMed]

22. Gawor, J.; Gawor, J.; Gromadka, R.; Zwijacz-Kozica, T.; Zieba, F. A modified method for molecular identification of Baylisascaris transfuga in European brown bears (Ursus arctos). Parasitol. Res. 2017, 116, 3447-3452. [CrossRef] [PubMed]

23. Strand, T.M.; Lundkvist, A. Rat-borne diseases at the horizon. A systematic review on infectious agents carried by rats in Europe 1995-2016. Infect. Ecol. Epidemiol. 2019, 9, 1553461. [CrossRef]

24. Thienpont, D.; Rochette, F.; Vanparijs, O.F.J. Diagnosing Helminthiasis by Coprological Examination, 2nd ed.; Jansen Research Foundation: Beerse, Belgium, 1986; p. 33.

25. Fedynich, A.M. Heterakis and Ascaridia. In Parasitic Diseases of Wild Birds; Atkinson, C.T., Thomas, N.J., Hunter, D.B., Eds.; John Wiley \& Sons: Oxford, UK, 2009; pp. 388-412.

26. Dos Santos, T.C.; Gallo, S.S.; Ederli, N.B.; Berto, B.P.; de Oliveira, F.C. Isospora dromaii n. sp. (Apicomplexa, Eimeriidae) isolated from emus, Dromaius novaehollandiae (Casuariiformes, Casuariidae). Parasitol. Res. 2014, 113, 3953-3955. [CrossRef] [PubMed]

27. Gallo, S.S.M.; Teixeiraa, C.S.; Ederlib, N.B.; Oliveiraa, F.C.R. Gastrointestinal parasites of a population of emus (Dromaius novaehollandiae) in Brazil. Braz. J. Biol. 2020, 80, 66-72. [CrossRef]

28. Khatri, K.; Maharjan, M. Gastrointestinal parasites of Emu (Dromaius novaehollandiae Latham, 1790) in Ostrich Nepal Pvt. Ltd. Gongoliya, Rupandehi. Nepal. J. Nat. Hist. Mus. 2016, 30, 269-273. [CrossRef]

29. Berto, B.P.; Flausino, W.; McIntosh, D.; Teixeira-Filho, W.L.; Lopes, C.W. Coccidia of New World passerine birds (Aves: Passeriformes): A review of Eimeria Schneider, 1875 and Isospora Schneider, 1881 (Apicomplexa: Eimeridae). Syst. Parasitol. 2011, 80, 159-204. [CrossRef] [PubMed] 
30. Mirzapour, A.; Kiani, H.; Mobedi, I.; Spotin, A.; Tabaei, S.J.S.; Rahimi, M. Frequency of intestinal parasites among zoo animal by morphometric criteria and first report of the Bivitellobilharzia nairi from Elephant (Elephasmaximus maximus) in Iran. Iran J. Parasitol. 2018, 13, 611-617.

31. Mir, A.Q.; Dua, K.; Singla, L.D.; Sharma, S.; Singh, M.P. Prevalence of parasitic infection in captive wild animals in Bir Moti Bagh mini zoo (Deer Park), Patiala, Punjab. Vet. World 2016, 9, 540-543. [CrossRef]

32. Atanaskova, E. Endo-parasites in wild animals at the zoological garden in Skopje, Macedonia. J. Threat. Taxa 2011, 3, 1955-1958. [CrossRef]

33. Lv, S.; Zhang, Y.; Steinmann, P.; Zhou, X.N.; Utzinger, J. Helminth infections of the central nervous system occurring in Southeast Asia and the Far East. Adv. Parasitol. 2010, 72, 351-408. [PubMed]

34. Otranto, D.; Deplazes, P. Zoonotic nematodes of wild carnivores. Int. J. Parasitol. Parasites Wildl. 2019, 9, 370-383. [CrossRef] [PubMed]

35. Rogers, L.L. Parasites of black bears of the Lake Superior region. J. Wildl. Dis. 1975, 11, 189-192. [CrossRef] [PubMed]

36. Bauer, C. Baylisascariosis-infections of animals and humans with unusual' roundworms. Vet. Parasitol. 2013, 193, 404-412. [CrossRef] [PubMed]

37. Kazacos, K.R.; Turek, J.J. Scanning electron microscopy of the eggs of Baylisascaris procyonis, Baylisascaris transfuga and Parascaris equorum, and their comparison with Toxocara canis and Ascaris suum. Proc. Helminthol. Soc. Wash 1983, 50, 36-42.

38. Papini, R.; Casarosa, L. Observations on the infectivity of Baylisascaris transfuga eggs for mice. Vet. Parasitol. 1994, 51, 283-288. [CrossRef]

39. Lee, R.M.; Moore, L.B.; Bottazzi, M.E.; Hotez, P.J. Toxocariasis in North America: A systematic review. PLoS Negl. Trop. Dis. 2014, 8, e3116. [CrossRef]

40. Eslahi, A.V.; Badri, M.; Khorshidi, A.; Hooshmand, E.; Hossein, H.; Taghipour, A.; Foroutan, M.; Firoozeh, F.; Zibaei, M. Prevalence of Toxocara and Toxascaris infection among human and animals in Iran with meta-analysis approach. BMC Infect. Dis. 2020, 20, 20. [CrossRef] [PubMed]

41. Maharjan, M. Endoparasites of primates and their zoonotic importance. Zoonoses Food Hyg. News 2015, 21, 2091-2932.

42. King, S.; Scholz, T. Trematodes of the family Opisthorchiidae: A minireview. Korean J. Parasitol. 2001, 39, 209-221. [CrossRef]

43. Seryodkin, I.V.; Goodrich, D.M.; Lewis, D.; Miquelle, D.G.; Esaulova, N.V.; Konyaev, S.V.; Quigley, K.S.; Roelke, M.; Petrunenko, Y.K.; Kerley, L.L.; et al. Infectious and endoparasitic deseases of the Amur tiger. Vestn. Kras GAU 2015, 12, 186-191.

44. Stuti, V.; Swaid, A.; Deepesh, S.; Mir, M. Parasitic ova and oocysts observed in intestinal contents of a Leopard (Panthera pardus)-A case report. J. Vet. Parasitol. 2012, 26, 170-171.

45. Liu, Q.; Li, M.W.; Wang, Z.D.; Zhao, G.H.; Zhu, X.Q. Human sparganosis, a neglected food borne zoonoses. Lancet Infect. Dis. 2015, 15, 1226-1235. [CrossRef]

46. Jeon, H.K.; Park, H.; Lee, D.; Choe, S.; Sohn, W.M.; Eom, K.S. Molecular Detection of Spirometra decipiens in the United States. Korean J. Parasitol. 2016, 54, 503-507. [CrossRef]

47. Yamasaki, H.; Sanpool, O.; Rodpai, R.; Sadaow, L.; Laummaunwai, P.; Un, M.; Thaanchomnang, T.; Laymanivong, S.; Aung, W.P.P.; Intapan, P.M.; et al. Spirometra species from Asia: Genetic diversity and taxonomic challenges. Parasitol. Int. 2021, 80, 102181. [CrossRef]

48. Jeon, H.K.; Park, H.; Lee, D.; Choe, S.; Kang, Y.; Bia, M.; Lee, S.H.; Eom, K.S. Complete sequence of the mitochondrial genome of Spirometra ranarum: Comparison with S. erinaceieuropaei and S. decipiens. Korean J. Parasitol. 2019, 57, 55-60. [CrossRef]

49. Sabu, L.; Lakshmanan, B.; Kumar, P.S. Occurrence of Human Sparganosis in Kerala. J. Parasit. Dis. 2015, 39, 777-779. [CrossRef] [PubMed]

50. Eom, K.S.; Park, H.; Lee, D.; Choe, S.; Kim, K.H.; Jeon, H.K. Mitochondrial genome sequences of Spirometra erinaceieuropaei and S. decipiens (Cestoda: Diphyllobothriidae). Korean J. Parasitol. 2015, 53, 455-463. [CrossRef]

51. Kamo, H. Guide to Identification of Diphyllobothriid Cestodes; Gendai kikaku: Tokyo, Japan, 1999.

52. Iwata, S. Experimental and morphological studies of Manson's tapeworm Diphyllobothrium erinacei (Rudolphi) special reference to its scientific name and relationship with Sparganum proliferum Ijima. Progr. Med. Parasitol. Jpn. 1972, 4, 536-590.

53. Gusset, M.; Dick, G. The global reach of zoos and aquariums in visitor numbers and conservation expenditures. Zoo Biol. 2011, 30, 566-569. [CrossRef]

54. Robinette, C.; Saffran, L.; Ruple, A.; Deem, S.L. Zoos and public health: A partnership on the One health frontier. One Health 2017, 3, 1-4. [CrossRef] [PubMed]

55. Soulsby, E.S.L. Helminths, Arthropods and Protozoa of Domesticated Animals, 7th ed.; Bailliere Tindall: London, UK, 1982.

56. Jeon, H.K.; Park, H.; Lee, D.; Choe, S.; Kim, K.H.; Huh, S.; Sohn, W.M.; Chai, J.Y.; Eom, K.S. Human infections with Spirometra decipiens plerocercoids identified by morphologic and genetic analyses in Korea. Korean J. Parasitol. 2015, 53, 299-305. [CrossRef]

57. Kumar, S.; Stecher, G.; Tamura, K. MEGA7: Molecular evolutionary genetics analysis version 7.0 for bigger datasets. Mol. Biol. Evol. 2016, 33, 1870-1874. [CrossRef] [PubMed]

58. Thompson, J.D.; Higgins, D.G.; Gibson, T.J. CLUSTAL W: Improving the sensitivity of progressive multiple sequence alignment through sequence weighting, position-specific gap penalties and weight matrix choice. Nucleic Acids Res. 1994, 22, 4673-4680. [CrossRef] [PubMed] 
59. Edgar, R.C. MUSCLE: Multiple sequence alignment with high accuracy and high throughput. Nucleic Acids Res. 2004, 32, 1792-1797. [CrossRef] [PubMed]

60. Lawrence, C. Hamilton. In Statistics with Stata: Version 12, 8th ed.; Cengage: Boston, MA, USA, 2013. 